\title{
Formação da identidade ocupacional em adolescentes
}

\author{
Jorge Castellá Sarriera \\ Marli Appel Silva \\ Cristina, Pigatto Kabbas \\ Vanessa Beckencamp Lópes \\ Pontifícia Universidade Católica do Rio Grande do Sul
}

\begin{abstract}
Resumo
Desenvolveu-se programa em escola da periferia de Porto Alegre para orientar adolescentes na busca de emprego. Visando conhecer características da construção da identidade vocacional, 36 jovens responderam, através da técnica de cartazes, a algumas questões. Observou-se que estavam desenvolvendo sua identidade ocupacional com projetos profissionais não inteiramente clarificados. Suas escolhas calcavam-se na fantasia, com elevadas expectativas quanto ao futuro. Entretanto, viam-se frente à necessidade de inserir-se no mercado de trabalho. Assim, concluiu-se que a inserção laboral representava a transformação da realidade social de exclusão e sofrimento, pela perspectiva futura de melhoria do nível de qualidade de vida.
\end{abstract}

Palavras-chave: Adolescência, Identidade ocupacional, Saúde mental, Mercado de trabalho.

\begin{abstract}
Occupational identity formation in adolescents

A psychological social program was developed in a school in the surroundings of Porto Alegre with the purpose of giving job search orientation to adolescents. The objective was to know the characteristics of their vocational identity, 36 youngsters answered, using posters posted on walls, some questions. It was observed that they were developing their occupational identity, even though their professional projects were not completely clarified. Their choices were based on fantasy, with high expectations concerning their future. Despite that, these adolescents face the necessity to enter the market. Thus, it was concluded that entering the job market represented the transformation of the exclusion and suffered social reality, into one of a future better quality of life.
\end{abstract}

Key words: Adolescence, Occupational identity, Mental health, Job market.

$\mathrm{N}$ este trabalho, estudamos aspectos relacionados à identidade ocupacional em adolescentes de classe popular. A necessidade de o jovem assumir compromissos e colocar-se frente à vida adulta significa uma profunda mudança de seu papel no mundo, levando-o a questionamentos, dúvidas e incertezas, o que Erikson (1968/1976) denominou de "crise da identidade" no período da adolescência.

Com base em Erikson (1968/1976), Márcia (1966) estudou empiricamente quatro modos de "estados de identidade" característicos da adolescência: "Identidade de Ganho", "de Moratória", "de Fase Emprestada" e "Difusa". A Identidade de Ganho é a mais adaptativa e a Difusa a menos adaptativa.
Na Identidade de Ganho, o adolescente experimenta uma fase de crise, considera escolhas de ocupação, avalia suas convicções e alcança uma resolução. Quanto à Identidade de Moratória, há compromissos bastante vagos. O adolescente tem momentos de preocupação com ele, mas as questões ocupacionais parecem-lhe sem solução. Já na Identidade de Fase Emprestada, o adolescente não experimentou ainda uma fase de crise. É difícil distinguir as metas dele das dos pais, pois tende a seguir o que os outros idealizaram para ele. Na Difusa, o adolescente pode ou não ter experimentado a crise característica da fase, mas ele não está muito concentrado em decidir-se a respeito de uma ocupação. Pode até mencionar preferências por ocupações, mas pode 
mudar facilmente suas idéias, pois tanto uma perspectiva quanto outra parecem boas para ele e não se mostra avesso a decidir-se por uma delas.

Kimmel e Weiner (1998) citam que o jovem desenvolve normativamente sua identidade quando toma decisões ocupacionais de maneira mais racional e sistemática, marcada pela exploração vocacional e autoconfiança. À medida que tem oportunidades, vai reduzindo gradualmente a lista de possibilidades, decidindo por uma profissão que seja de seu interesse e compatível com suas aptidões. Entretanto, quanto mais difusa é a identidade do jovem, mais ele tende a evitar a exploração vocacional por completo, bem como tomar decisões quanto à escolha profissional. Caso as tome, opta pelo que acredita correto ou conveniente, sem reflexões mais aprofundadas.

Assim, percebemos que o desenvolvimento da identidade pessoal (quem eu sou?) tem íntima relação com a escolha vocacional (quem eu quero ser?) em consonância com os interesses e habilidades do adolescente (do que eu gosto?).

\section{Identidade ocupacional e exclusão social}

A identidade ocupacional, que é um dos componentes da identidade pessoal, diz respeito a como uma pessoa integra "suas diferentes identificações e sabe o que quer fazer, de que modo e em que contexto" (Bohoslavsky , 1977/ 1998, p. 49).

A escolha ocupacional é, então, o reflexo de como o jovem lida com sua crise de identidade, lançando mão de suas capacidades em prol de uma atitude ocupacional. Esta "maneira" de lidar institui, portanto, a identidade ocupacional, que é um colocar-se no mundo de forma a responder aos anseios, expectativas e habilidades do "eu" adolescente, resultando na escolha de uma profissão.

No desenvolvimento da identidade ocupacional ocorre a análise do "contexto sociocultural", das instituições, das organizações existentes, das tecnologias disponíveis etc., relacionando-se às oportunidades que os adolescentes podem vivenciar, significando "quando, onde e como" será a profissão escolhida. O jovem está, portanto, na etapa da "exploração", em busca de respostas à escolha profissional e da definição de seus projetos de vida (Bohoslavsky, 1977/1998).

Logo, se a identidade ocupacional desenvolve-se frente ao contexto social, como esta se processa em adolescentes de classe popular que vivem um grau de exclusão social? Tendo em vista que a exclusão social pode ser sinônimo de desemprego para esses jovens ou de um trabalho pouco qualificado e precário.

Segundo Castell (1998), os desempregados apresentam um sentido de invalidez e de não pertencimento social denominado de "desfiliação social". Wickert (1999) comenta que o trabalho é estruturante da identidade e que o desemprego traz sofrimento psíquico e, por conseguinte, coloca em risco a saúde mental.

Pesquisa realizada por Sarriera e Verdin (1996) demonstra que jovens desempregados apresentam menor nível de bem-estar psicológico, devido a um sentimento de "vazio" e impotência frente às dificuldades de inserção no mercado de trabalho que os desmotiva para obterem atitudes mais assertivas e perseverantes na busca do mesmo.

Seligmann-Silva (1994) comenta que o desemprego para o jovem "constitui um duro impedimento para seus projetos" (p. 277), colocando-o diante de um sofrimento solitário. A procura frustrada do primeiro trabalho "poderá produzir, como conseqüência, o adoecer, a apatia ou a marginalidade, ao invés do jovem adquirir um determinado 'status' social ou auto-afirmar-se como cidadão ativo e produtivo" (Sarriera, 1995, pp. 72-73).

Constatamos, então, que a vivência do desemprego pode trazer um nível de sofrimento aos jovens e ter influências na saúde mental e, portanto, nas definições da identidade ocupacional.

Por outro lado, ao conseguirem ingressar no mercado de trabalho, estes jovem costumam iniciarem em empregos com baixa qualificação. Gomes (1990) afirma que aos jovens destinam-se os empregos com condições mais precárias, salários rebaixados, jornadas extensivas, o que os colocam, muitas vezes, frente ao descumprimento das leis trabalhistas.

Seligmann-Silva (1994) comenta que o trabalho, dependendo de sua estruturação, "tanto poderá fortalecer a saúde mental quanto levar a distúrbios que se expressarão coletivamente em termos psicossociais e/ou individuais, em manifestações psicossomáticas ou psiquiátricas" (p. 46). Logo, a saúde mental estará dependente de como o trabalho é articulado e vivenciado pelos trabalhadores. No caso do jovem de classe popular que está mais a mercê de trabalhos mais precários, podemos pensar que ele poderá estar sujeito a distúrbios psicossociais em uma fase em que ainda está definindo a identidade ocupacional e a pessoal.

De acordo com Sarriera, Schwarcz, Câmara, Bem e Gandarillas (1996), o "vínculo (trabalho) pessoa-sociedade possibilita um sentido de participação e utilidade" (p. 92). O trabalho poderá ser estruturante da identidade se puder proporcionar ao jovem um sentido de vida, facilitando suas escolhas profissionais à medida que possa ser fonte de informações e aprendizagem, além de permitir novos contatos sociais, ampliando a rede de amizades e a social. Entretanto, os jovens poderão encontrar o sentido de vida frente à possibilidade de desemprego ou de um trabalho precário e de pouca qualificação?

Assim, as questões norteadoras desta pesquisa dizem respeito à compreensão do desenvolvimento da identidade 
ocupacional em adolescentes com baixo nível econômicocultural, que se encontram frente à necessidade de inserção no mercado de trabalho. Para tanto, buscamos uma reflexão sobre tais questões.

\section{Método}

\section{Sujeitos}

Participaram deste estudo 36 adolescentes pertencentes à classe popular, que frequientavam os cursos de beleza, hotelaria e auxiliar de escritório, oferecidos por uma escola profissionalizante, em julho de 1998. Dentre estes, 91,7\% eram do sexo feminino e $8,3 \%$ do sexo masculino, com idades entre 14 e 21 anos $(X=16,92, D P=1,75)$.

\section{Instrumento}

A presente pesquisa localiza-se no contexto da aplicação de um Programa de Intervenção para a inserção sociolaboral dos jovens. O Programa foi dividido em três módulos, sendo que os objetivos trabalhados respectivamente foram: “A construção do projeto profissional", "Treinamento em Habilidades Sociais" e, finalmente, "Cidadania e Trabalho".

No presente artigo, as informações analisadas foram respectivas a uma das técnicas utilizadas no primeiro módulo, que consistia na "elaboração de cartazes", na qual cada adolescente, individualmente, deveria expressar, através de recortes de jornais e revistas, desenhos ou frases, suas características pessoais (autoconceito) e seus interesses pessoais e profissionais, além de sentimentos e expectativas quanto ao futuro laboral, realizando um relato referente ao significado de seu cartaz, após a elaboração. Para tanto, foram apresentadas as seguintes questões: “Quem sou eu?”, “Do que gosto?" e "O que pretendo profissionalmente?"

Apoiando-se na análise qualitativa, a análise das informações baseou-se no conteúdo expresso pelos 36 sujeitos, incluindo figuras e frases, a partir da Análise Categorial de Argilaga (1995), buscando-se categorias para discussão a partir das respostas dos adolescentes, frente às questões norteadoras propostas.

\section{Resultados}

\section{Identidade do jovem}

Observamos, através dos cartazes elaborados pelos adolescentes, que eles têm a percepção de que estão saindo da fase infantil e que terão de se inserir no "mundo adulto", conforme frases citadas por eles: "gosto de arrumar meus brinquedos de infância"; "eu me interesso muito em crescer, ter uma vida melhor".

De fato, estão definindo a identidade pessoal, percebendo-se por suas características internas: "sou muito sonhado- ra e também insegura; às vezes triste com o que acontece" e a partir de suas características físicas: "tenho 1,67 cm., sou morena cor mista, cabelo castanho escuro, olhos castanho escuro, sou magra”. Colocam-se também na dimensão do tempo e do espaço: "tenho 18 anos e nasci em Porto Alegre" - situando-se regional e culturalmente.

Em relação à crise de identidade que estão passando, falam de seus sentimentos: "pessoas felizes têm a mania de enfrentar seus medos" - o que pode significar dúvidas e incertezas que vivenciam. Seus dizeres também se referem às noções a respeito da necessidade de enfrentarem estes sentimentos para se prepararem para o futuro.

\section{Estados da identidade}

Estes jovens parecem estar em uma vivência mais para o estado difuso do que de ganho, pois, em geral, há uma certa indefinição quanto às escolhas, principalmente à profissional: "o que eu vou ser estou endúvida"1.

Os projetos futuros apresentam-se pouco definidos, havendo a visão de futuro ainda com pouca clareza das escolhas profissionais: "gostaria que, no futuro, eu tivesse um bom emprego que me pague bem de acordo do que eu faço no serviço. Para mais tarde quando eu pegar um emprego ter bastante curso e mais qualificação entre outras pessoas".

Entretanto, estes jovens não parecem estar fixados no estado difuso e sim se desenvolvendo, pois apresentam bom nível de exploração, vínculos afetivos e interesse pela vida.

\section{A exploração pessoal e do meio}

Para os adolescentes estudados, o lazer está vinculado às atividades físicas e com influência da cultura em que estão inseridos: "gosto - figura de uma torcida organizada de futebol - Torcer; Torcer - figura de um grupo de pagode Dança, Dança - figura de um jogador de futebol - futebol”.

A televisão aparece como influenciando as escolhas, provavelmente sendo importante na formação de uma cultura jovem para esses adolescentes: "gravura de propaganda da emissora MTV - 24 horas no ar - Music Television; Eu adoro a Music Television Brasileira”.

No vínculo com o outro, a família aparece para alguns como figuras de afeto: "sou muito feliz com a minha família”. Mas é o grupo de amigos que se revela como vínculo significativo pela frequiência com que aparece: "gosto de fazer tudo sair, brincar, ter muitos amigos".

Poucos adolescentes referem-se ao estudo e ao trabaIho: "gosto de estudar, e gosto de ler, sou uma pessoa que gosto de trabalhar" - como resposta à questão "do que eu gosto".

Observamos que para estes adolescentes a exploração do meio está em boa medida vinculada ao lazer (atividades físicas e televisão), ao contato com grupos e com a família. 


\section{Escolha ocupacional}

Poucos jovens trouxeram escolhas mais definidas na esfera ocupacional: "no futuro gostária de me profissionaliza em veterinária; pretendo ser dona de um restaurante ou lancheria; profissionalmente quero chegar a ser uma policial civil e tambem se eu tivesse sorte, ser uma artista profissional.; profissionalmente quero chegar a ser sercretária ou professora até mesmo cosinheira profissional".

Embora citem nomes de profissões, revelam implicitamente dúvidas e incertezas em suas escolhas laborais. Querem ser uma coisa e/ou "também" outra, faltando maior clareza em relação a onde, quando e como farão para chegar a ser tais profissionais.

\section{Exclusão social}

Constatamos que estes jovens apontam uma baixa formação escolar, indicada pelos erros ortográficos apresentados: "bom, quando eu arrumar um bom emprego quero construí, minha casa; e colocar minha filha num bom colégio". Para Forrester (1997), a formação educacional coloca o jovem diante de uma angústia profunda à medida que reforça a idéia de exclusão social, ocasionando dificuldades de ingresso em uma dimensão mais intelectualizada.

Visto que buscam inserir-se no mercado de trabalho, o baixo nível de formação dos jovens participantes deste estudo pode colocá-los no grupo de desemprego de longa duração. Entretanto, ao perceberem a realidade social em que vivem, revelam um sentimento de querer transcendê-lo: "alcançar todos os meus objetivos vencer as dificuldades; uma vida melhor do que essa que Eu tenho!!!; quero que os meus filhos tenham uma vida bem diferente da minha um bom estudo etc...; figura de uma grande mulher sorridente olhando seu talão de cheques".

\section{Metas e a esperança}

Embora apresentem metas ainda difusas: "ter bastante cursos; trabalha e aprender muitas coisas para o meu bem e o bem do Brasil" - os jovens demonstram, de uma forma geral, um desejo de melhorar suas condições socioecônomicas, vinculando seus projetos futuros a aquisições materiais: "e principalmente ter uma bela casa para melhor criar os meus filhos e minha vida melhor e ter de tudo o que a vida tem de bom - gravura: terraço de uma casa, com vista da cidade e mesa posta com talheres e pratos; ter um automóvel - gravura com um carro".

O conforto e estabilidade são condições esperadas para este futuro. Gostariam de um emprego seguro que garantisse o sustento e as condições socioeconômicas que não dispõem na atualidade: "eu pretendo voltar a estudar, para conseguir um bom emprego - frases coladas: você vive realmente bem? e você quer melhorar de vida? ter um bom emprego? - gravura: cozinheira segurando pratos de comida em uma cozinha com a frase ter como viver da minha profissão".

Revelam a expectativa de vencerem as dificuldades para alcançarem um futuro melhor: "alcançar todos os meus objetivos vencer as dificuldades; lutar, vencer todas as barreiras". Neste futuro, contemplam o desejo da felicidade: "pretendo correr muito em busca de minha felicidade moral, intelectual, socioeconômica e familiar-figura de um atleta pronto para a corrida com os dizeres aprender cada vez mais".

Assim, suas falas referem-se à luta por uma libertação: "eu sei que vou conseguir; quando eu conseguir um bom emprego eu vou pensar $=$ eu dei $=$ a volta por cima VALEU'. Podemos compreender que a libertação de um sofrimento implícito está relacionada com a inserção no trabalho, pois esta proporcionará um nível de qualidade de vida superior ao atual.

\section{Discussão}

O sofrimento frente à exclusão social (Forrester, 1997) é lido nas entrelinhas das falas dos jovens desta pesquisa. Percebemos quase que um grito de desespero por parte deles: "uma vida melhor do que essa que eu tenho!!!", traduzindo o desejo de suplantar a realidade atual vivenciada, revelando sonhos e esperanças de um futuro feliz.

Estes jovens vislumbram alcançar tal felicidade através do trabalho, pois para eles este representa um caminho para uma vida melhor e um sentido de existência pessoal. A inserção laboral significa o "passe de mágica" para este futuro, que lhes propiciará ter, segundo eles, seu próprio negócio, um emprego estável, uma boa qualidade de vida, um futuro condigno para si e seus familiares. Ou seja, eles almejam encontrar na vida profissional a plena realização da identidade pessoal e ocupacional.

As expectativas sobre e o desejo de um futuro feliz fazem parte de uma adolescência normativa, de acordo com as definições que Kimmel e Weiner (1998). Entretanto, é necessário olharmos a conjuntura atual do mercado de trabalho. No caso do Brasil, a taxa de desemprego é significativa. A taxa de desemprego aberto nacional foi de 6,4\%, em fevereiro de 2001, segundo a Pesquisa Mensal de Emprego - PME (IBGE, 2001).

Dessa forma, consideramos que os jovens desta pesquisa poderão incorporar o grupo de desempregados porque, além do desemprego ser significativo no Brasil, este tem maior incidência para essa faixa etária, associando-se ainda ao fato de que os jovens estudados apresentam baixa formação educacional. Este último fator impede os jovens de estarem devidamente preparados para o ingresso no trabalho. $\mathrm{O}$ desemprego alcança principalmente jovens de baixo nível de formação e reciclagem (Capdevila, 1993), como é o caso destes adolescentes. 
De acordo com Forrester (1997), a escola e os docentes normalmente representam os que os excluem, colocando-os frente ao sofrimento que vivenciam em sua realidade social. A escolarização é vista como uma chance desses jovens ultrapassarem as barreiras sociais que lhes são impostas. Esta chance causa uma angústia profunda "que sublinha sua miséria e o perigo que os ameaça” (p. 76).

Dentro desse enfoque, para os jovens desta pesquisa, a escolaridade parece de fato ter significado um ambiente de exclusão. Assim, eles fazem do trabalho um depositário de suas expectativas em relação ao futuro.

Além do mais, ao conseguirem ingressar no mercado de trabalho apresentando um nível de formação deficitário, provavelmente caberá a estes jovens os empregos que requeiram menor qualificação, portanto, que ofereçam condições mais precárias, salários rebaixados, talvez jornadas extensivas e descumprimento das leis trabalhistas.

Observamos que um paradoxo poderá ser colocado para estes adolescentes: ou enfrentar o desemprego, ou trabalhar em atividades de baixa qualificação e com condições precárias. Assim, nos perguntamos: como será o futuro deles? Esta fala de um dos jovens estudados é representativa: “às vezes tenho medo do futuro" (figura de uma jovem mulher).

Principalmente pela fase do desenvolvimento em que se encontram, situações de desemprego ou de trabalhos com condições precárias poderão ter implicações na saúde mental destes jovens e, conseqüentemente, no desenvolvimento da identidade ocupacional. Portanto, as tentativas de escolhas profissionais e de elaboração de projetos ocupacionais poderão sofrer prejuízos frente ao mercado de trabalho, que tende a oferecer poucas alternativas para jovens de classe popular.

Aliás, os adolescentes aqui estudados revelam projetos ocupacionais ainda indefinidos. Percebemos que para estes jovens tornou-se difícil a identificação com papéis de competência ideologicamente construídos a priori e incógnitos dentro da realidade social vivida. Suas identificações mostraram-se mais vinculadas às figuras da mídia, principalmente da televisão, referida como uma constituinte importante do lazer. Poucos se referiram aos estudos e trabalho como escolhas dentro de seus gostos pessoais.

Os projetos ocupacionais ainda indefinidos se coadunam com a dificuldade na aquisição de emprego, tendo em vista que os jovens que apresentam projetos definidos e plausíveis quando partem para a inserção laboral são mais eficazes (Depolo, 1993, citado por Sarriera et al., 1996). Os jovens aqui pesquisados têm muitas esperanças e sonhos, mas não sabem bem o que, como e de que maneira fazer para concretizar seus ideais. Dessa forma, a falta de um projeto definido ocupacional, aliada a uma baixa escolarização, tende a colocá-los com maior incidência frente ao desemprego.
Na melhor das hipóteses, possuem adiante uma perspectiva: "uma vida ligada ao salário e dependente dele. Aquilo que se costuma chamar de uma vida útil" (Forrester, 1997, p. 75). Ou melhor, estes jovens ao ingressarem no mercado de trabalho estarão à mercê da existência de empregos disponíveis, que são cada vez mais escassos, bem como tenderão a aceitar os salários pagos, que nem sempre são compatíveis com uma existência digna, ou mesmo estarão passíveis de trabalhos com precárias condições.

Portanto, o trabalho que utiliza "uma mão-de-obra barata" e que desconsidera o jovem, a fase em que vive, seu desenvolvimento e seu futuro, terá provavelmente influência significativa na formação de sua identidade ocupacional.

\section{Considerações Finais}

Os jovens estudados estão desenvolvendo sua identidade ocupacional e apontaram um nível de expectativa significativo em relação à escolha de uma profissão, ainda muito calcado na fantasia. Assim, podemos questionar quais os tipos de projetos ou programas poderiam ser realizados para melhor prepará-los para o mercado, a fim de enfrentarem com mais adequação os dados de realidade. Programas que não sejam meramente adaptativos, mas que os façam refletir sobre as suas condições de vida, de forma a buscarem seus sonhos e, principalmente, continuarem com a esperança, aspecto que se revelou representativo.

Acreditamos que existem alternativas, embora a realidade apresente um paradoxo de desemprego e de baixas condições de trabalho.

Para tanto, programas que enfoquem tal problemática terão que repensar as formas de trabalho existentes, com alternativas inovadoras que possam, em alguma medida, garantir a inserção destes jovens no mercado de trabalho e promover a manutenção de sua saúde mental.

Para que encontremos estas novas alternativas, necessitamos ampliar discussões e, a partir delas, efetivar mudanças. Estas questões competem a todos nós, participantes desta sociedade.

\section{Agradecimentos}

Os autores agradecem à FAPERGS pelo apoio ao projeto que deu origem ao presente texto.

\section{Referências}

Argilaga, M. T. A. (1995). Tratamiento cualitativo de dados. In M. T. Anguera, J. Arnau, M. A. Rosario \& J. P. G. Vallejo (Orgs.), Métodos de investigación psicológica (pp. 549-579). Madrid: Síntesis Psicología. Bohoslavsky, R. (1998). Orientação Vocacional: a estratégia clínica (11 ed.). São Paulo: Martins Fontes (Texto original publicado em 1977).

Capdevila, J. M. (1993). Orientación Ocupacional. Madrid: CEAC. 
Castell, R. (1998). As metamorfoses da questão social: uma crônica do salário. Petrópolis: Vozes.

Erickson, E. H. (1976). Identidade: juventude e crise ( $2^{\mathrm{a}}$ ed.). Rio de Janeiro: Zahar (Texto original publicado em 1968).

Forrester, V. (1997). O horror econômico. São Paulo: Editora da Universidade Estadual Paulista.

Gomes, C. A. (1990). O jovem e o desafio do trabalho. São Paulo: EPU.

IBGE - Instituto Brasileiro de Geografia e Estatística. (2001). Pesquisa Mensal de Emprego - PME (On-line). Disponível: http://www.ibge.net/ ibge/estatistica/ indicadores/trabalhoerendimento/pme/default.shtm

Kimmel, D. C., \& Weiner, I. B. (1998). La adolescencia: una transición hacia el desarrollo. Barcelona: Ariel.
Marcia, J. E. (1966). Development and validation of ego identity status. Journal of Personality and Social Psychology, 3(5), 551-558.

Sarriera, J. C. (1995). Enfoque ecológico das relações saúde-trabalho. Psico, $26(2), 65-80$

Sarriera, J. C., Schwarcz, C., Câmara, S. G., Bem, L. A., \& Gandarillas, M. A. (1996). Bem-estar psicológico dos jovens porto-alegrenses. Psico, 27(2), 79-95.

Sarriera, J. C., \& Verdin, R. (1996). Os jovens a procura de trabalho: uma análise qualitativa. Psico, 27(1), 59-70.

Seligmann-Silva, E. (1994). O desgaste mental no trabalho dominado. Rio de Janeiro: Cortez.

Wickert, L. F. (1999). O adoecer psíquico do desempregado. Psicologia Ciência e Profissão, 19(1), 66-75.

\section{Nota}

1 Os erros ortográficos foram transcritos literalmente das escritas dos jovens.

Jorge Castellá Sarriera, doutor em Psicologia Social pela Universidad Autonoma de Madrid (Espanha), é professor do Programa de Pós-Graduação em Psicologia, da Pontifícia Universidade Católica do Rio Grande do Sul.

Marli Silva Appel é psicóloga e mestre em Psicologia Social e da Personalidade pela Pontifícia Universidade Católica do Rio Grande do Sul.

Cristina Pigatto Kabbas, psicóloga, economista, ex-bolsista do programa PIBIC/CNPq/PUCRS, e Vanessa Beckencamp Lópes, psicóloga, ex-bolsista FAPERGS, são membros do Grupo de Pesquisa em Psicologia Comunitária, Pontifícia Universidade Católica do Rio Grande do Sul.

Endereço para correspondência: Pontifícia Universidade Católica do Rio Grande do Sul, Faculdade de Psicologia, Pós-Graduação em Psicologia Social e da Personalidade, Grupo de Pesquisa em Psicologia Comunitária. Av. Ipiranga, 6681, Prédio 11, sala 929, $9^{\circ}$. andar. 90619-900, Porto Alegre, RS. Tel (51)320.3500, ramal 3633. E-mail: sarriera@ zaz.com.br. 